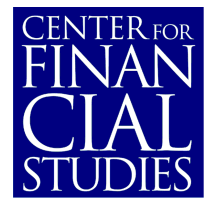

No. $2002 / 07$

\title{
Exit Timing of Venture Capitalists in the Course of an Initial Public Offering
}

Werner Neus and Uwe Walz

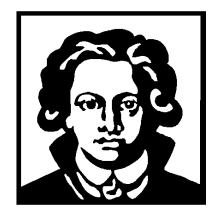


No. $2002 / 07$

Exit Timing of Venture Capitalists in the Course of an Initial Public Offering

Werner Neus and Uwe Walz 
No. $2002 / 07$

Exit Timing of Venture Capitalists in the Course of an Initial Public Offering

Werner Neus and Uwe Walz 


\title{
Exit Timing of Venture Capitalists in the Course of an Initial Public Offering
}

\author{
Werner Neus* and Uwe Walz**
}

June $2002^{* \star *}$

\begin{abstract}
:
We analyze the desinvestment decision of venture capitalists in the course of an IPO of their portfolio firms. The capital market learns of the project quality only in the period following the IPO. Venture capitalists with high-quality firms face a trade-off between immediately selling their stake in the venture at a price below the true value and having to wait until the true value is revealed. We show that the dilemma may be resolved via a reputation-acquiring mechanism in a repeated game set-up. Thereby, we can explain, e.g., the advent of "hot-issue market behavior" involving early disinvestments and a high degree of price uncertainty. Furthermore, we provide a new rationale for underpricing. Young venture capitalists may use underpricing as a device for credibly committing themselves to acquiring reputation.
\end{abstract}

JEL Classification: G24, G14, D82

Keywords: Exit Decisions, Venture Capital, IPO, Underpricing

\footnotetext{
Werner Neus, University of Tübingen, Department of Banking, Mohlstr. 36, D-72074 Tübingen, email: werner.neus@uni-tuebingen.de.

** Uwe Walz, University of Tübingen, Department of Economics, Mohlstr. 36, D-72074 Tübingen, email: uwe.walz@uni-tuebingen.de, CEPR, London, UK, and Center for Financial Studies, Taunusanlage 6, D-60329 Frankfurt am Main.

*** We would like to thank seminar participants at the Universities of Frankfurt and Bonn for suggestions and comments. We are also grateful to an anonymous referee for the very helpful and constructive comments on an earlier version of the paper.
} 


\section{Introduction}

One of the key issues in venture capital finance is the exiting process (cf. Gompers and Lerner, 2000). Due to the structure of the venture capital industry (often closed-end funds are used) and due to their comparative advantage in start-up finance, venture capital firms are engaged in their portfolio firms for only a limited period of time. Unwinding the engagement in the portfolio firm in the course of the exit process is therefore one of the most important aspects of success for venture capital firms. Of the different exit channels, the initial public offering (IPO) of shares of the portfolio firms is often regarded as the most essential one in terms of its contribution to a venture capitalist's eturn. Therefore, IPOs play a decisive role in venture capital investments (see, e.g., Black and Gilson, 1998). It is, however, quite surprising to observe that venture capitalists are by no means disposed to sell (all) their shares at the time of the IPO (see Barry et al. 1990).

This observation is the starting point of the present paper. We analyze the disinvestment decision of venture capital firms (VCs) in the course of an IPO. We isolate the determinants of the VCs' decision to unwind their investment at the time of the IPO and explore potential motives for postponing the disinvestment to a later period. In contrast to the analysis by Gompers (1996), who considers the timing of the IPO, we take the date of the IPO as given and analyze the optimal disinvestment time period (i.e. at the time of the IPO or later). We thereby take into account the fact that VCs, as inside investors, are typically better informed, at least for some period of time, about the quality of their portfolio firms than are outside investors in the capital market. That is, whereas informational asymmetries do exist at the time of the IPO, they vanish over time. Therefore, VCs wanting to disinvest a single high-quality portfolio firm face the following 
trade-off. On the one hand, late disinvestments are associated with large opportunity costs; on the other hand, they may help to overcome informational costs (i.e. a low price for such ventures).

By extending our basic set-up of a single-issue case to a repeated set-up, we take into account that venture capitalists are identifiable, repeated players in the IPO market. We show that such a repeated-game set-up allows venture capitalists to establish a reputation as honest players in the IPO market, i.e. for not selling overvalued shares. As we are less interested in a subtle game-theoretic model than in economic consequences, we model reputation as simple as possible and use an infinitely repeated game with a perfectly observable deviant behavior. In models like this (e.g. Klein and Leffler, 1981), reputation is the trust outside investors have with respect to the correctness of a VC's announcement of project quality, implicitly given by the pricing of a venture. Therefore, reputation is a binary variable: VCs may or may not have a reputation for a correct pricing.

This kind of reputation (as well as any other, more differentiated kind) allows VCs to overcome the costs associated with the informational asymmetries in the IPO market. Within such a reputational equilibrium market inefficiencies can be resolved. This corresponds to the more general "certification hypothesis" on the role of investment bankers in the process of issuing shares in public offerings (e.g. Beatty and Ritter, 1986; Booth and Smith, 1986). The importance of reputation is stressed in many theoretical as well as empirical studies into venture capital (see, e.g., Amit et al. 1998). Here, reputation serves as a credible commitment to a correct pricing of issues. We ask under which circumstances such a reputational equilibrium will emerge. VCs may differ in their experience, their market share, and the composition of their portfolio. We inves- 
tigate which types of venture capitalists are most likely to be able to establish a reputation for credible announcements of the (high) quality of portfolio firms in the course of the IPO. This kind of reputation will enable VCs to sell their venture at the time of the IPO at the "correct" price. We show that seasoned venture capitalists with a high market share are those signaling the quality of their firms best. This conforms with empirical research on the timing of disinvestment in the course of an IPO (see Lin and Smith, 1998).

In a second step, we extend our basic model by allowing for the possibility of $\mathrm{n}$ vesting in the quality of portfolio firms via advisory services and management support for an additional period. This is a matter of importance, as the provision of managerial resources belongs to the essential tasks of venture capitalists (see Hellmann, 1998). Once again, we isolate the types of VCs willing to invest for an additional period in their portfolio firms and analyze the impact of this option on the distribution of disinvestment timings. In a third step, we introduce underpricing as an additional device for acquiring reputation in the IPO market that involves not selling overvalued firms. We show that particularly young and unseasoned venture capitalists may be led to underprice their high-quality firms in order to acquire one of the most-sought-after goods in the venture capital market: reputation. By underpricing, young VCs are able to overcome (at least partially) the inefficiencies in the IPO market.

There are a number of studies which are related to our study. Gompers (1996) investigates the timing of the IPO of venture-backed firms and provides arguments that VCs force their firms to go public too early. In an empirical paper, Gompers and Lerner (1998) investigate one very prominent way for VCs to liquidate the positions in their 
portfolios, namely via the distribution of shares (rather than cash) to their investors. In so doing, VCs delegate the task of selling shares to their investors.

Our paper complements the empirical study of Lin and Smith (1998), who analyze the disinvestment decision of VCs using US data. However, their study lacks a theoretical framework in which the disinvestment decisions can be analyzed in detail.

Underpricing is one of the most prominent features in the IPO literature, often viewed as a signal for project quality (e.g. Grinblatt and Hwang, 1989; Allen and Faulhaber, 1989). Alternatively, underpricing may be a compensation for a winner's curse in a set-up where some of the outside investors have superior information on the value of the firm (Rock, 1986). Furthermore, underpricing may emerge as the result of moralhazard problems between the investment banker (as the agent) and their client (Baron, 1982). We present an additional rationale for underpricing: Particularly for young VCs, underpricing may serve as a credible commitment to building up a reputation for the correct pricing of issues.

Finally, there is some relation between our paper and Stocken (2000), who examines the credibility of a manager's disclosure of privately obtained information to investors in a repeated-game set-up. In his model, sufficiently patient managers almost always report truthfully, whereas in our paper the credibility of the VCs depends on certain attributes.

The paper is organized as follows. In the next section, we present the basic structure of our model and outline the equilibria emerging for a one-shot game, i.e. for a single issue. The second part of this section contains a detailed analysis of potential reputational equilibria. In sections three and four, we analyze straightforward extensions of our basic setting. In section three, we allow for the option of value-enhancing invest- 
ments by the venture capitalist and examine the impact of this option on the exit strategy of the venture capitalist in different settings. In section four, we come up with a new explanation for the underpricing exhibited in the course of initial public offerings. In section five, we provide a short conclusion and a discussion of our results.

\section{The basic model}

\section{II.1 The single-issue case}

We are considering venture capitalists wanting to unwind their investment in one of their portfolio firms in the course of an initial public offering or at a later point in time. The venture capitalist has invested either in a good firm (the value of his investment is $1+?>1$ ) or in a (relatively) "bad" firm. ${ }^{1}$ In the latter case the value of his investment is normalized to 1 . The parameter ? therefore measures the degree of quality heterogeneity between the two types of firms and the ex-ante risk from the outside investors' point of view, respectively. In order to simplify the set-up, we restrict the exit decision of the VC to two periods. Either the VCs sell their shares immediately during the IPO process (in $t=1$ ) or they wait one further period and sell their investment in $t=2$. There is an informational asymmetry in the sense that the VC (the inside investor) already knows the quality of their particular firm in $t=1$, whereas the outside investors in the capital market only know the average percentage a of good firms. After one period, the investors in the capital market have learnt sufficiently much (e.g. through secondary market prices) to be able to distinguish a good from a bad project in $\mathrm{t}=2$.

\footnotetext{
1 This terminology clearly does not describe the quality of the firms from an overall point of view, given that the portfolio firms listed via an IPO already depict a positive selection in a VC's portfolio.
} 
Thus, we assume an informationally efficient secondary market, while the IPO market lacks efficiency. Even though, generally speaking, market efficiency might be questionable, there is no doubt that the secondary market is more efficient than the IPO market. Without any further information, ${ }^{2}$, rational investors in competitive capital markets will pay the average price $a \cdot(1+?)+(1-a) \cdot 1=1+a \cdot ?^{3}$ In the second period, true values are paid for the firms: $1+$ ? for the good firm and 1 for the bad firm. In the following, we will refer to the first (second) one as a type G (B) firm.

The VC discounts sales proceeds in $\mathrm{t}=2$ by the factor $\beta(\beta<1)$. The discount factor of the $\mathrm{VC}$ between the two periods is smaller than that of the public, reflecting the typically higher preference for liquidity in the VC industry. In order to save notation, we normalize the discount factor of the general public to unity and consider $\quad \beta$ as being the difference in the discount factor between the two groups. ${ }^{4}$ The smaller $B$ is, the more pronounced the (relative) demand for liquidity on the part of the VC. Given that the $\mathrm{VC}$ is typically restricted in their ability to finance new projects, we also can view this discount factor as a measure of the availability of profitable new investment for the VC, i.e. as measure of the innovative capabilities of the economy as a whole. Thus, a low $B$ might be associated with a "hot issue market".

\footnotetext{
2 Obviously, there are many sources of information for the external investor about a firm's track record (like financial statements and reports). In addition, there are civil as well as criminal sanctions for false statements. But these information and sanctions refer to records on past developments. Assessments of the firm's future prospect are always subjective. Therefore, it is very difficult to sanction wrong assessments of expected future developments. It is in this sense that we allow for informational asymmetries between the $\mathrm{VC}$ and the investors in the capital market.

3 In order to avoid the need to distinguish between the value of the firm and that of the VC investment, we focus, without loss of generality, only on that part of the portfolio firm which is in the VC's possession.

4 A perfect substitute for this would be to assume that the value of the firms increases between the two periods in a manner inversely proportional to the discount factor of the outside investor.
} 
The crucial question of our further analysis concerns the VC's strategy to unwind their engagement in either a type $B$ or $G$ firm. In both cases, they can either disinvest in $t=1$ or $t=2$. $^{5}$ We may distinguish four possible situations. The first situation is the one in which VCs are not, independent of the quality of their portfolio firm, willing to sell their shares in the initial period. Selling the respective firms in $t=2$ enables the $\mathrm{VC}$ to always receive a price equal to the true value of the firm. In discounted terms, this yields sales proceeds for unwinding the investment in a type $B$ firm of $P_{B, 2}=\beta$ and the investment in a type $G$ firm of $P_{G, 2}=\beta \cdot(1+$ ? ) .

In the first period, outside investors cannot observe the quality of the individual project. Hence, if both types of projects are sold in the first period, a pooling price will emerge in the capital market:

$$
\mathrm{P}_{1}^{\mathrm{pool}}=\mathrm{a} \cdot(1+?)+(1-\mathrm{a}) \cdot 1=1+\mathrm{a} \cdot ? .
$$

In a situation in which only type $G$ (B) projects are sold, outside investors in competitive capital markets will end up paying $\mathrm{P}_{\mathrm{G}, 1}=1+? \quad\left(\mathrm{P}_{\mathrm{B}, 1}=1\right)$.

Obviously, not all four situations can be equilibrium configurations. Due to the fact that all informational asymmetries will have vanished in period 2, VCs with type B firms will never be willing to wait, since they will always receive a higher price (in discounted terms) when selling in period $t=1$. Therefore the first situation, as well as the one in which only type $\mathrm{G}$ shares are sold in the initial period, can be excluded as can-

\footnotetext{
Empirical evidence shows (cf., e.g., Lin and Smith, 1998) that VCs typically maintain a certain portion of their ventures' shares at the time of the IPO. If we allow for continuously distributes types of ventures and a choice of the part of shares sold at the IPO, our model captures this result, as well. An exposition of this alternative modeling is given in the appendix. As our basic model serves as a basis for the detailed discussion of more subtle issues, we use the binary variable in what follows.
} 
didates for an equilibrium. Hence, two equilibrium configurations remain. ${ }^{6}$ In the first one, the pooling equilibrium, both types of firms are sold in the first period. In the second one, the separating equilibrium, type $B$ shares are sold in period $t=1$, whereas type $G$ shares remain in the portfolio of the respective $\mathrm{VC}$ until $\mathrm{t}=2$. In the pooling equilibrium, we observe the pooling price; while with the separating equilibrium, type B projects are sold at their true value in $t=1$ and type $G$ investments are unwound at their true value in the second period.

Which of the two potential equilibrium configurations occurs depends on the parameters. The pooling situation actually constitutes an equilibrium if VCs with a good project prefer to wait and sell at a discounted price of $B \cdot(1+$ ?) rather than at the pooling price $1+\mathrm{a} \cdot$ ? (see eq. 1). Given that VCs with a type B project obviously always prefer selling above the true value at the pooling price in period 1, we obtain the following condition:

$$
1+\mathrm{a} \cdot ?>\beta \cdot(1+?)
$$

Hence, pooling, i.e. selling both types of firms in the initial period, constitutes an equilibrium if

$$
\beta<\beta_{\mathrm{P}} \equiv \frac{1+\mathrm{a} \cdot ?}{1+?},
$$

where, for the sake of concreteness, we assume that a separating equilibrium results in the case of indifference. In contrast, a separating equilibrium requires that VCs with a type $G$ project in their portfolio prefer to wait and sell at the true value of the project rather than at the pooling price.

\footnotetext{
All over the paper we neglect any equilibria in randomized strategies.
} 
That is,

$$
1+\mathrm{a} \cdot ? \leq \beta \cdot(1+?)
$$

for $B \geq \beta_{P}$ has to hold. Hence, eq. (3) describes the separating line between the two types of equilibria. ${ }^{7}$ The larger the proportion a of high-quality projects and the smaller the difference in value ? between the two types of projects, the more likely the pooling equilibrium becomes. In such cases, the pooling price is relatively more attractive, causing the VC to prefer an early exit. The same is true if the VC has a pronounced preference for liquidity (a low B), which has the effect of making early selling strategies more attractive.

\section{II.2 A reputational game}

Typically VCs are not engaged in only one IPO during their economic life; typically they play a repeated game in the IPO market. Moreover, VCs are identifiable players in the IPO market. An essential feature of the venture capital industry in general may be said to be the establishment of reputation capital.

\footnotetext{
For certain parameter values, both pooling and separating constitute a Bayesian equilibrium. In this case of a multiple equilibrium, type $G$ 's payoff in a pooling equilibrium exceeds the payoff in the separating equilibrium. Therefore, from an economic point of view, $\beta_{\mathrm{P}}$ unambiguously separates the two equilibria. Furthermore, with regard to the existence of a reputational equilibrium the proposed equilibrium selection creates a higher hurdle than does any alternative.
} 
Building up reputation is essential in this type of industry with its myriads of informational asymmetries (see Black and Gilson, 1998; Sahlman, 1990). With respect to exiting via the IPO market, there are two important aspects to reputation.

On the one hand, VCs, especially young ones, have a strong ncentive to build up a reputation with their investors by means of realizing a successful IPO with high returns as soon as possible. This facilitates refinancing for the VC (especially for firsttime funds) when it comes to raising new money for a follow-up fund. We capture this aspect with our discount factor for the VC. On the other hand, VCs may have a strong incentive, when playing the IPO market more than once, to establish a reputation for being an honest partner, i.e. not disclosing any false information or, equivalently, not mispricing the issue. We model this aspect with the help of a repeated game. Within this supergame, additional future profits may serve as a device to commit oneself to a cooperative strategy with outside investors. In order to avoid destroying reputation, VCs may decide to relinquish reporting the false type of their own portfolio firm.

Some remarks on the modeling of reputation might be necessary. As stated in the introduction, we intend to model reputational effects as simple as possible. Generally, there are two types of models which capture the notion of reputation.

In the first approach (cf. Milgrom and Roberts, 1982; Kreps and Wilson, 1982), reputation is defined as belief about unknown characteristics, where the proportion a of good projects might be such a characteristic. Starting from a-priori probabilities, beliefs evolve in a Bayesian updating process, taking into account the observation of an imperfect signal for the quality parameter (e.g. the quality of a certain venture). Reputation then can be measured by the a-posteriori probability for being the good type. 
Whereas these models explicate the process of building up or losing reputation, they equire substantial calculations.

The second approach (see, e.g., Klein and Leffler, 1981; Shapiro, 1983) is considerably simpler. Reputation here might be described as the trust outside investors attribute to the pricing of a certain VC. If the incentive compatibility constraint is met, investors suppose the pricing of ventures to be correct unless they observe a cheating behavior by the VC. Note that it is perfectly observable ex post whether the VC plays cooperatively or deviates. Under these conditions, a supergame consisting of an infinitely epeated game typically has a multiple equilibrium. To be more precise, any feasible, individually rational payoff can be enforced as a subgame-perfect equilibrium, if a deviation is punished by playing the equilibrium of the one-shot game and the agents are sufficiently patient. This famous "folk theorem" has been formalized by Friedman (1971). However, among the plethora of equilibria, the truth-telling equilibrium is of major importance, as it resolves any misallocation of capital. As the truth-telling equilibrium becomes the easier viable, the harder are the sanctions, a complete and final loss of reputation in case of a one-time deviation leads to the most efficient equilibrium.

Our main interest is the notion that profitable business is forgone by a false pricing. As we are less interested in the process of building up reputation, the infinitely epeated cheap talk game framework is adequate for our purposes. In what follows we focus on the existence of truth-telling equilibria where $\mathrm{VC}$ perform a correct pricing of ventures and outside investors ascribe a positive reputation (in the sense of credibility) to the $\mathrm{VC}$ as long as no mispricing is detected. The $\mathrm{VC}$ has invested in a number of portfolio firms, some of which are periodically going public. The percentage of good firms, i.e. of a firm being a type $G$ firm, is a for each venture financed by a certain 
VC. The probability for such a type $G$ project is therefore constant over time from the viewpoint of the individual VC.

In what follows, we investigate the conditions that must obtain for a viable reputational effect. A reputational equilibrium is characterized by the fact that VCs report the true quality of their portfolio firms and hence sell them at their respective true value in the initial period. If a truth-telling strategy is feasible, VCs with a type G project overcome the costs associated with either waiting or pooling. The VC's announcement becomes credible in light of the mechanisms of the reputation game.

Obviously, a VC with a type $\mathrm{G}$ project prefers such a reputational equilibrium to each of the one-shot game outcomes described in the previous subsections. Therefore, the individual rationality of a VC with a type $\mathrm{G}$ project does not place any further restrictions on a reputational equilibrium. Instead the crucial question is whether a VC with a type $B$ firm is willing to report the true quality of their portfolio firm. In case of truthful reporting, the $\mathrm{VC}$ is able to stick to the cooperative outcome and can expect to sell a type $G$ firm at the correct price in $t=1$ in future issue rounds. A cheating VC gains in the initial (1.e., the cheating) round by selling a type $\mathrm{B}$ project at the value of a type $\mathrm{G}$ firm, thus receiving $1+$ ? rather than only 1 (the correct value). The truthtelling strategy yields the VC with a type B firm a discounted value for selling the portfolio firms in the present and all following issues of

$$
\mathrm{P}_{\mathrm{B}}^{\mathrm{tr}}=1+\sum_{\mathrm{t}=1}^{\infty} \mathrm{d}^{\mathrm{t}}(\mathrm{a} \cdot(1+?)+(1-\mathrm{a}) \cdot 1)=1+\frac{\mathrm{d}}{1-\mathrm{d}} \cdot(1+\mathrm{a} \cdot ?)
$$

with d denoting the rate at which VCs discount revenues across two subsequent issues. The discount factor $\mathrm{d}$ reflects the refinancing possibilities of the $\mathrm{VC}$ or, almost equivalently, the density with which VCs enter the IPO market in the future. We interpret the 
latter as the market share of the VC. That is, the closer $d$ is to one, the better the refinancing possibilities of the $\mathrm{VC}$ are and the higher their market share.

The discount factors $\beta$ and $\mathrm{d}$ ought not be confused: $\beta$ is a measure for the time period between the IPO and the seasoned offering of the shares held by the VC; whereas $\mathrm{d}$ measures the distance between two ventures to be disinvested by the VC at the time of the IPO. The following diagram may serve to clarify the distinction.

(( Insert figure 1 about here. ))

The difference between these measures basically expresses the fact that the time span between the IPO of two different ventures of a VC on the one hand and the IPO and the seasoned offerings of shares of the same venture on the other hand may be different. An alternative representation to ours is to use a common discount factor for a given period of time and to allow for two different time variables. In order to save notation, we have chosen the above procedure and decided to use two "different discount factors". As we do not analyze overlapping ventures, $B$ should be larger than $d$. Of course, in general ventures might be overlapping. But within the model, overlapping ventures would not allow us to explicate the flow of information as precise as we do.

By electing to cheat, a VC with a type $\mathrm{B}$ firm will gain with respect to the present issues, but may experience lower returns in future due to loss of reputation. Future returns without reputation are identical to those in the one-shot game. If condition (3) holds, the pooling equilibrium is the outcome of the one-shot game. In this case, the discounted value with cheating is 


$$
\mathrm{P}_{\mathrm{B}}^{\mathrm{ch}}(\mathrm{pool})=1+?+\sum_{\mathrm{t}=1}^{\infty} \mathrm{d}^{\mathrm{t}} \cdot(1+\mathrm{a} \cdot ?)=1+?+\frac{\mathrm{d}}{1-\mathrm{d}} \cdot(1+\mathrm{a} \cdot ?)
$$

Comparing eqs. (5) and (6) reveals that $\mathrm{P}_{\mathrm{B}}^{\mathrm{tr}}<\mathrm{P}_{\mathrm{B}}^{\mathrm{ch}}$ (pool), i.e. cheating dways pays. This simply reflects the fact that, on average, in the pooling equilibrium, the true prices of the projects are paid. Hence, in this case, the costs of cheating are zero. Given the costs of truth-telling in the initial period, cheating is obviously the optimal strategy. As a result, no reputational equilibrium exists if $\beta<\beta_{\mathrm{P}}$.

Matters are different if condition (3) does not hold and a separating equilibrium emerges in the one-shot game. In this parameter constellation, the expected discounted flow of revenues for a cheating $\mathrm{VC}$ with a type $\mathrm{B}$ firm amounts to

$$
\begin{aligned}
\mathrm{P}_{\mathrm{B}}^{\mathrm{ch}}(\mathrm{sep}) & =1+?+\sum_{\mathrm{t}=1}^{\infty} \mathrm{d}^{\mathrm{t}} \cdot(\mathrm{a} \cdot \beta \cdot(1+?)+(1-\mathrm{a}) \cdot 1) \\
& =1+?+\frac{\mathrm{d}}{1-\mathrm{d}} \cdot((1+\mathrm{a} \cdot ?)-\mathrm{a} \cdot(1-\beta) \cdot(1+?)) .
\end{aligned}
$$

Once again, the latter part of the RHS expression reflects the expected discounted revenues occurring after the "cheating" period.

Comparing (7) and (5) yields the following necessary condition for a reputational equilibrium

$$
\beta \leq \beta_{R} \equiv 1-\frac{1-d}{a \cdot d} \cdot \frac{?}{1+?} .
$$

Taking condition (3) into account shows that a reputational equilibrium prevails if and only if $\beta_{P} \leq \beta \leq \beta_{R}$. A pooling equilibrium exists with $B<\beta_{P}$, whereas a separating 
equilibrium obtains for $\beta>\max \left\{\beta_{R}, \beta_{P}\right\} .^{8} \quad$ Figure 2 illustrates the different equilibrium configurations emerging with different parameter settings.

(( Insert figure 2 about here. ))

A reputational equilibrium emerges in the area between line A, depicting eq. (3), and line $\mathrm{B}$, describing eq. (8) in an a- $\beta$-space. This area is non-empty if $\beta_{R}>\beta_{P}$. Taking a closer look on this condition reveals

$$
\beta_{R}-\beta_{P}=\frac{?}{1+?} \cdot \frac{(1-a) \cdot a \cdot d-(1-d)}{a \cdot d} .
$$

For this expression to be positive,

$$
\mathrm{d}>\frac{1}{1+\mathrm{a}-\mathrm{a}^{2}}
$$

must hold. ${ }^{9}$ Hence, three main factors bear on the likelihood of a reputational equilibrium. First, a glance at eq. (10) reveals that a larger discount factor d makes, ceteris paribus, the reputational equilibrium more likely. Graphically speaking, a higher $d$ shifts line B upwards while leaving line A unaffected. This is indeed a straightforward intuition. A VC with a larger $\mathrm{d}$ has more to bse in the event of deviation from a truthtelling strategy. That is, a VC appearing more often in this issue market has a stronger incentive to build up reputation, since it is of greater benefit to sell the future type $G$ firms at their true value in the initial period of the IPO process. An immediate corollary

\footnotetext{
Again, for the sake of concreteness, we assume that $\beta=\beta_{R}$ leads to a reputational equilibrium, given that $\beta_{\mathrm{R}} \geq \beta_{\mathrm{P}}$.

9 While, in general, $\beta_{\mathrm{P}}$ might be negative, (10) implies that $\beta_{\mathrm{P}}$ is positive.
} 
of this point is that established venture capitalists find it much easier to signal their own credibility.

Parameter a, which serves to measure the proportion of good projects, has a nonmonotonous impact on the likelihood of a reputational equilibrium occurring. This is due to the fact that there are two opposing effects on the incentive to stick to a cooperative strategy.

On the one hand, a very large a leads to a pooling equilibrium, since the subsidies inherent to type B firms that come with the pooling price become less important, which, in turn, makes pooling relatively less unattractive. With a pooling equilibrium in the one-shot game, there are no sanctions on the cheating VC. Therefore, with a too high a we will not observe a reputational equilibrium. On the other hand, a too small a implies that, on average, VCs expect very few type $G$ investments in future, which also reduces the cost of the cheating strategy. Taking these two effects together, it is apparent that a reputational equilibrium is only feasible for a medium-ranged a.

The third parameter affecting the likelihood of a reputational equilibrium is the factor at which cash flows are discounted between the two periods of one particular ísue. Once again, a reputational equilibrium obtains for intermediate values of $\beta$ With a low $\beta$ VCs with a type $G$ firm prefer the pooling equilibrium, making the cooperative outcome infeasible. With a high $\quad$ (i.e. a low preference for present cash flows) the cost of cheating, i.e. being able to sell type $G$ projects in future issues in $t=2$ rather than in $t=1$ at their true value, is small, making the reputational equilibrium unsustainable.

Finally, the value difference between the two types of projects identically influences the likelihood of a reputational equilibrium in a positive way. This is best seen by 
looking at eq. (9). Given that the second quotient is positive, a larger ? increases the permitted region for $B$.

The following numerical examples illustrate once again the overall situation and the likelihood of a reputational equilibrium.

(( Insert table I about here. $))$

As stated in the introduction, Stocken (2000) presents a model similar to ours. In his model, the information of both the managers (equivalent to our VCs) and the investors is imperfect. But unlike in our paper, in his model managers only receive some revenue if their project is of the good type. Thus the punishment is more severe, which provides an even stronger incentive to report truthfully. This leads to the result that the manager almost always reports truthfully if they are sufficiently patient, while in our model some further restrictions have to be met.

\section{Investments in project quality and the decision to disinvest}

One of the main characteristics of venture capitalists is that not only do they invest financial capital in their portfolio firms, but also inject their expertise and knowledge concerning the management of firms. In a nutshell, they operate as permanent consultants to their portfolio firms. Given that they are specialists in this role, it is natural for them to develop a comparative advantage in this regard.

We incorporate this crucial aspect of venture capital into our model by allowing for the possibility of value-enhancing investments on the part of the $\mathrm{VC}$. We isolate the 
circumstances under which a VC with a type $\mathrm{B}$ project is willing to invest in a nonexploited potential in order to secure an increase in value. The VC with a type B project faces a trade-off between investing management resources at cost $\mathrm{I}$ in their venture, causing this venture to become a type $\mathrm{G}$ project after one period with probability q $\quad(0<\mathrm{q}<1)$, and not investing (and thus sticking with the low quality of the firm). Obviously, the investment in the quality of the firm in period 1 is linked to, and has consequences on, the decision to disinvest. In the following, we will analyze the conditions under which a $\mathrm{VC}$ has an incentive to undertake a value-increasing investment, as well as the consequences this has for the overall disinvestment strategy.

A value-increasing investment clearly excludes an immediate disinvestment in period $\mathrm{t}=1$. Hence, and in contrast with the preceding section, it is not always preferable to sell type $\mathrm{B}$ ventures immediately in period $\mathrm{t}=1$; rather it may pay to invest and wait for another period in which disinvestment then takes place. We pursue our analysis by analyzing the single-issue case first. Then, we consider the option of a reputational equilibrium in the course of ongoing issues. ${ }^{10}$

\section{III.1 Value-increasing investments and disinvestment in the single-issue case}

Since VCs with a type B project may have an incentive to undertake investments with a potential for increased value, we encounter three equilibrium candidates. First, there is a pooling situation in $t=1$ if both types of ventures are sold in the initial period. Sec-

\footnotetext{
10 At period $\mathrm{t}=1$, the investment is not observable to the outside investors. Otherwise, observing a non-investment might have an informational content for outsiders.
} 
ond, the separating equilibrium with type $B$ firms sold in $t=1$ and type $G$ firms not sold before $\mathrm{t}=2$ remains a viable equilibrium. And due to the nvestment option, there is a situation with both firms selling in $t=2$ which becomes a feasible equilibrium candidate. We call the latter a "late-pooling" equilibrium.

It is fairly straightforward to see that with a pooling equilibrium prevailing in $t=1$, it never pays for an investment in $t=1$ to be undertaken for type $B$. This can be shown in the following manner. Against the background of a pooling equilibrium in $\mathrm{t}=1$, investment only takes place if $1+\mathrm{a} \cdot ? \leq-\mathrm{I}+\mathrm{\beta} \cdot(1+\mathrm{q} \cdot ?)$ or

$$
\beta \geq \beta_{\mathrm{I}}^{\mathrm{P}} \equiv \frac{1+\mathrm{a} \cdot ?+\mathrm{I}}{1+\mathrm{q} \cdot ?}
$$

Comparing $\quad \beta_{\mathrm{I}}^{\mathrm{P}} \quad$ with $\quad \beta_{\mathrm{P}}$ reveals that the latter is always smaller, i.e. the pooling condition (see eq. 3) is always more restrictive than the investment criterion. If a pooling equilibrium prevails, investments in $\mathrm{t}=1$ are never profitable from the point of view of the individual investor. That this is so is intuitively obvious. With a pooling equilibrium, it does not pay to wait until $t=2$ with type $G$ firms. Hence, nvesting in value enhancements which yield a type $G$ with a probability of less than one (and which are at the same time costly) can never make sense. The implicit subsidy of type B firms is too pronounced in this setting to allow for a profitable investment.

An immediate corollary of this is that pooling implies underinvestment in value enhancement. Comparing the investment incentives with the incentives in a symmetric information setting reveals the informational costs associated with the investment decision in $t=1$. In contrast to a symmetric information setting in which type $B$ firms yield a price of 1 , in the Bayesian pooling we find that equilibrium type $B$ firms are subsidized by the amount a ? leading to a too low level of investment. This distortion 
is the more pronounced, the higher the VC's proportion of type $G$ projects. Tracing this back to a superior project selection, we obtain an explanation for the specialization by different VCs in different investment stages. VCs with a comparative advantage in the early stage (and hence a high a) have a low incentive to put the finishing touch on their portfolio firms, i.e. to invest heavily in later stages (and vice versa).

Investment in value enhancement may only occur with $B \geq \beta_{P} \cdot{ }^{11}$ VCs with a type B firm face two alternatives. Either they sell their shares immediately at the price given in the prevailing separating equilibrium, i.e. 1. Alternatively, they can bear the investment costs I receiving an expected payoff of $1+q \cdot ?$. Hence, investments are profitable if and only if $1 \leq-\mathrm{I}+\beta \cdot(1+\mathrm{q} \cdot ?)$ or

$$
\beta \geq \beta_{\mathrm{I}}^{\mathrm{S}} \equiv \frac{1+\mathrm{I}}{1+\mathrm{q} \cdot ?} .
$$

This implies that we observe a separating equilibrium ${ }^{12}$ (without investment) in the range $\beta \in\left[\beta_{\mathrm{P}}, \beta_{\mathrm{I}}^{S}\right.$ ), whereas for $\beta \geq \beta_{\mathrm{I}}^{S}$, an equilibrium with "late pooling" occurs. In the latter case, VCs invest $I$ in the type $B$ firms and sell these ventures in $t=2$ at their true value. This is the more likely, the larger $q$ and $\beta$ are and the smaller $I$ is. Firms with a comparative advantage in late stage financing (and therefore a low I and a relatively large q) will invest in $\mathrm{t}=1$ and typically disinvest in later stages.

11 There exist sets of parameters where (12) and (3) hold simultaneously. Again, in this case, the early pooling equilibrium dominates the late pooling equilibrium for a $\mathrm{VC}$ with a type $G$ project. Therefore, as was stated above, it is only with $\beta \geq \beta_{\mathrm{P}}$ that investment in value-enhancement may occur.

12 Against the background of a separating equilibrium and a potential price of a type $B$ venture equal to one (the true value), the investment decision is efficient, i.e., the investment incentives are not distorted. In other words, eq. (12) is equivalent to a positive net present value of the investment. 


\section{III.2 Reputational equilibrium in the presence of profitable investments}

Even in the presence of the investment option in $t=1$, type $G$ ventures are never sold at the true value in $t=1$ in the single-issue case. This implies inefficiently low returns for this type of ventures from the point of view of the $\mathrm{VC}$ and results in an underincentive to engage in financing start-up firms. Hence it is important once again to ask whether this shortcoming can be resolved via a reputational mechanism. In particular, we would like to know whether the investment opportunity makes such a solution more or less likely.

We focus only on situations where the investment turns out to be profitable from the point of view of the individual $\mathrm{VC}$ in our asymmetric information setting, i.e. with $\beta \geq \beta_{I}^{S}$. This condition is equivalent to a positive net present value (NPV) of the investment. In all other situations, the investment option will not be exercised and therefore does not alter the results discussed in the previous subsection. With $\beta \geq \beta_{I}^{S}$, deviators from the cooperative strategy anticipate that "late pooling" has occurred. Type G ventures are sold at their true value in the respective second period. With type B projects, it turns out that it pays to invest in $\mathrm{t}=1$, thus leading to a quality jump with probability q.

Thus, the cooperative strategy yields the following discounted cash flow for the VC:

$$
\begin{aligned}
\mathrm{P}_{\mathrm{B}}^{\mathrm{tr}} \text { (inv) } & =(-\mathrm{I}+\beta \cdot(1+\mathrm{q} \cdot ?))+\sum_{\mathrm{t}=1}^{\infty} \mathrm{d}^{\mathrm{t}} \cdot(\mathrm{a} \cdot(1+?)+(1-\mathrm{a}) \cdot(-\mathrm{I}+\beta \cdot(1+\mathrm{q} \cdot ?))) \\
& =(-\mathrm{I}+\beta \cdot(1+\mathrm{q} \cdot ?))+\frac{\mathrm{d}}{1-\mathrm{d}} \cdot(\mathrm{a} \cdot(1+?)+(1-\mathrm{a}) \cdot(-\mathrm{I}+\beta \cdot(1+\mathrm{q} \cdot ?)))
\end{aligned}
$$


The RHS of (13) consists of two parts: the revenues from selling the bad firm in the course of the current offering (equal to $-I+\beta \cdot(1+q \cdot ?)$ ) and the discounted cash flow for all future periods (the remaining part on the RHS).

In the event of cheating, the VC bses the advantage of immediately disinvesting type $\mathrm{G}$ projects in future issues. The present value of revenues therefore amounts to

$$
\begin{aligned}
\mathrm{P}_{\mathrm{B}}^{\mathrm{ch}}(\text { inv }) & =1+?+\sum_{\mathrm{t}=1}^{\infty} \mathrm{d}^{\mathrm{t}} \cdot(\mathrm{a} \cdot \beta \cdot(1+?)+(1-\mathrm{a}) \cdot(-\mathrm{I}+\beta \cdot(1+\mathrm{q} \cdot ?))) \\
& =1+?+\frac{\mathrm{d}}{1-\mathrm{d}} \cdot(\mathrm{a} \cdot \beta \cdot(1+?)+(1-\mathrm{a}) \cdot(-\mathrm{I}+\beta \cdot(1+\mathrm{q} \cdot ?)))
\end{aligned}
$$

Comparing eq. (13) and (14) gives us the following condition for a reputational equilibrium:

$$
\beta \leq \beta_{R, I} \equiv 1-\frac{1-\mathrm{d}}{\mathrm{a} \cdot \mathrm{d}} \cdot \frac{?-\mathrm{NPV}}{1+?},
$$

where NPV of the investment is given by

$$
\mathrm{NPV}=-(1+\mathrm{I})+\beta \cdot(1+\mathrm{q} \cdot ?) .
$$

Obviously, condition (15) is weaker that inequality (8), because $\beta_{R, I}>\beta_{R}$, which in turn reflects the fact that a positive NPV is a necessary condition for late pooling. Given an incentive to engage in a value-enhancing investment, the credibility of the $\mathrm{VC}$ increases. While the costs of cheating are not altered by the investment option, the possible gains of cheating decrease by the amount of the NPV. As the NPV itself is positively correlated with $B$, there is an additional second order effect.

An overview on the different equilibria with the investment option is given in Figure 3, with condition (12) depicted as line C. 
(( Insert figure 3 about here. ))

To sum up, if VCs are highly specialized in managing portfolio firms and increasing their value in later stages, it turns out to be profitable to exit from type $G$ firms immediately, while VCs with low-quality firms remain invested in their portfolio firms and are committed to trying to increase the latter's value with the help of management and advisory support. This result is just the opposite of the one in the basic model in section II.1. Reputational effects enable VCs to sell type G firms early without incurring any loss, whereas the investment option gives an incentive to VCs with a type B firm to improve its value.

\section{Underpricing as a reputational device}

In the preceding sections, we assumed that the characteristics of VCs do not change over time. Constant parameters over time, however, imply that all learning effects and advantages associated with experience are completely neglected. In this section, we aim to incorporate these aspects by allowing the parameters characterizing a $\mathrm{VC}$ to change. More precisely, we model the incentives of young VCs to build up reputation capital. This is done against the background of the often-mentioned argument that in a market characterized by such a high-degree of informational asymmetries as the VC market is, the building up of reputation is crucial (see e.g. Megginson and Weiss, 1991). Allowing for changing parameters over time also allows us to distinguish different types of VCs: on the one hand, young ones with little or no track record and a small number of potential IPO candidates; and on the other hand, old ones with a long history of successful investments as well as a constant flow of IPOs. 
We transpose this into our model by assuming that a young venture capital firm starts with a low $\delta$, since the time span between two potential IPOs is long and insecure. Over time, as the $\mathrm{VC}$ grows older this parameter grows too, reflecting the fact that the VC has more successful firms in their portfolio which will be sold via an IPO. Thus, experienced VCs have a higher market share than younger ones. In order to model this basic idea as simply as possible, we allow for two different $d$ : a low $d_{1}$ in the first period of time (associated with the first ssue); and a higher $\mathrm{d}_{2}\left(\mathrm{~d}_{2}>\mathrm{d}_{1}\right)$ for all future periods in which the $\mathrm{VC}$ has grown mature. Some alternatives to this modeling are discussed below.

Our basic framework has shown that a low $\mathrm{d}$ is definitely a handicap to realization of a reputational equilibrium. Initially, therefore, it is a problem for a young VC to build up reputation capital. We argue, however, that a young VC may use underpricing as an instrument to compensate for this handicap and so build up reputation anyway. Underpricing type $\mathrm{G}$ projects enables VCs to commit themselves in a credible manner to the reputational equilibrium. We show that only young VCs have an incentive to underprice IPOs, whereas established VCs do not need to pursue this strategy. Thus, while the increased experience leads to an increase in market share enabling the VCs to prove their trustworthiness, underpricing resolves the lack of "natural" credibility of a young VC. This is in line with empirical esearch showing that IPOs with a mature VC as their lead investor do not show any signs of significant underpricing, whereas this is the case when the VC is young (see Gompers, 1996). Our explanation of the often-observed phenomenon of underpricing stands in contrast to most explanations in the literature. In other papers, underpricing serves as a signal of project quality (e.g. Grinblatt and Hwang, 1989; Allen and Faulhaber, 1989) or as compensation for a winner's curse (Rock, 1986), whereas in our scenario it is simply a device to build up reputation. 
In order to focus on our argument, we neglect the possibility of value-increasing investments and consider only situations in which young VCs cannot credibly commit themselves to a reputational equilibrium (whereas experienced ones can). Taking the two different values for $\mathrm{d}$ into account, $\mathrm{d}_{1}$ for the issue under consideration and $\mathrm{d}_{2}$ for all remaining ones, and then feed these into eqs. (5) and (6), we obtain a modified condition under which a young VC is excluded from a reputational equilibrium:

$$
\beta>\beta_{\mathrm{R}}^{\mathrm{Y}} \equiv 1-\frac{1-\mathrm{d}_{2}}{\mathrm{a} \cdot \mathrm{d}_{1}} \cdot \frac{?}{1+?} .
$$

At the same time, an experienced VC may obtain the profits from reputation if

$$
\beta \leq \beta_{\mathrm{R}}^{\mathrm{E}} \equiv 1-\frac{1-\mathrm{d}_{2}}{\mathrm{a} \cdot \mathrm{d}_{2}} \cdot \frac{?}{1+?} .
$$

For $d_{1}<d_{2}$ there is always a parameter constellation for which (8') and (8'") hold $\dot{\mathrm{s}}$ multaneously. In order to highlight our argument as sharply as possible, we focus only on situations where in the single-issue case a separating equilibrium obtains, i.e. $\beta \geq \beta_{\mathrm{P}}$.

In the situation described above, a young VC cannot realize a reputational equilibrium by selling type $G$ projects at their true value in $t=1$. At first glance, only the separating scenario is a feasible equilibrium. We will show, however, that underpricing, i.e. selling type $G$ projects in $t=1$ at a price of $1+$ ? $-\mathrm{U}$ (where $\mathrm{U}$ measures the amount of underpricing), constitutes a reputational equilibrium and a way out of this dlemma. Hence, underpricing is considered to be a device which compensates for the low 
level of experience of a young VC. ${ }^{13}$ For a young VC with a type $\mathrm{G}$ project, this device is associated with lower costs than is the non-occurrence of an immediate reputational effect.

For a reputational equilibrium with underpricing, two additional requirements must be fulfilled. First, it should be in the self-interest of a young VC with a type G project to participate in the scheme with underpricing. Second, a young VC with a type B project must have an incentive to stick to the cooperative equilibrium without cheating.

With respect to the first condition, we assume that after the nitial period a young $\mathrm{VC}$ becomes experienced. That is, after the initial period, the payoff to the VC with a type $G$ project is the same, no matter whether a reputational equilibrium is initiated with the first issue or not. Due to (8') we know that the experienced VC will remain with the reputational equilibrium if cheating has not taken place with the first issue. Hence, VCs with type $G$ firms only have to compare their payoff with the initial issue resulting from an underpricing strategy with the one stemming from the separating equilibrium. Underpricing is preferred if

$$
1+?-\mathrm{U} \geq \beta \cdot(1+?)
$$

or

$$
\mathrm{U} \leq \mathrm{U}_{\mathrm{G}} \equiv(1-\beta) \cdot(1+?)
$$

\footnotetext{
13 One might argue that underpricing is also a solution for an experienced VC to resort to in situations where $(8$ ', ) does not hold. It turns out, however, that this does not work. Either VCs with a type $G$ project do not have an incentive to underprice or VCs with type $B$ projects are unwilling to stick to the reputational equilibrium and try to imitate type $G$ projects. This is due to the fact that underpricing, while lowering the immediate gain from cheating, also reduces the implicit sanctions arising in later periods (the opportunity costs of cheating in later periods are reduced). In the aggregate, underpricing does not work as a solution for experienced VCs, if (8') does not hold.
} 
With respect to the second requirement, we must make sure that VCs with type B projects do not want to deviate from the reputational equilibrium with underpricing. Again taking into account that the reputational equilibrium implies that for all future periods type $G$ projects can be sold at their true value, while with cheating a separating equilibrium evolves, the discounted income stream with underpricing is

$$
\mathrm{P}_{\mathrm{B}}^{\mathrm{tr}}(\text { underpr })=1+\frac{\mathrm{d}_{1}}{1-\mathrm{d}_{2}}(\mathrm{a} \cdot(1+?)+(1-\mathrm{a}) \cdot 1)
$$

In the case of cheating we obtain

$$
\mathrm{P}_{\mathrm{B}}^{\mathrm{ch}}(\text { underpr })=1+?-\mathrm{U}+\frac{\mathrm{d}_{1}}{1-\mathrm{d}_{2}} \cdot(\mathrm{a} \cdot \mathrm{B} \cdot(1+?)+(1-\mathrm{a}) \cdot 1)
$$

Comparing the two equations leads us to the following second condition for a stable reputational equilibrium with underpricing:

$$
\mathrm{U} \geq \mathrm{U}_{\mathrm{B}} \equiv ?-\frac{\mathrm{d}_{1}}{1-\mathrm{d}_{2}} \cdot(\mathrm{a} \cdot(1+?) \cdot(1-\beta))
$$

A necessary condition for a reputational equilibrium is therefore $U_{B} \leq U_{G}$. This requires that

$$
\beta \leq \beta_{\mathrm{R}}^{\text {underpr }} \equiv 1-\frac{1-\mathrm{d}_{2}}{1-\mathrm{d}_{2}+\mathrm{a} \cdot \mathrm{d}_{1}} \cdot \frac{?}{1+?}
$$

A reputational equilibrium with underpricing exists if the conditions expressed in eqs. (8'), (8') and (19) as well as $\beta \geq \beta_{\mathrm{P}}$ hold.

Table II illustrates the impact of different parameter settings on the likelihood of a reputational equilibrium with underpricing.

(( Insert table II about here. )) 
The first three cases show that a reputational equilibrium with underpricing may exist. The larger the difference between the discount factors of young and experienced VCs the larger the parameter range for which an underpricing regime prevails (see cases 1 and 2). Generally, the likelihood of such an equilibrium is larger the larger ? is (cases 2 and 3). With low absolute discount factors, the reputational equilibrium even for experienced VCs does not prevail anymore (case 4). If, finally, the proportion of good projects a is very small, VCs with a type $\mathrm{G}$ project prefer the pooling equilibrium and the underpricing equilibrium does not prevail either (case 5).

The results are summarized in Figure 4 with line D representing condition (19).

(( Insert figure 4 about here. ))

In order to show that our underpricing explanation is quite robust against variation in our set-up we investigate the idea that inexperienced and experienced VC differ in the proportion of expected $\mathrm{G}$ firms in future IPO rounds. Whereas experienced VCs expect a proportion of a for all future periods, an inexperienced VC expects only the proportion $a_{1} \quad\left(a>a_{1}\right)$ of type $G$ firms for the next period and a for all future periods. Calculating the critical $B$ for this set-up gives us similar results as above. Cases 6 and 7 delineate example for this alternative interpretation. Looking at these examples reveals 
that they are in a reasonable parameter range. Here, too, a larger $d$ broadens the parameter range for which a reputational equilibrium with underpricing exists. ${ }^{14}$

Given that a reputational equilibrium prevails, a young VC will choose underpricing to the extent that $\mathrm{U}=\mathrm{U}_{\mathrm{B}}$, since they have no reason to provide an even lower price of their type $\mathrm{G}$ project. A lower price would only reduce the income of the $\mathrm{VC}$ without any additional gains. We can therefore use eq. (18) to investigate the comparative statics underlying the extent of the underpricing phenomenon in our model. Taking a closer look at this equation reveals that the extent of underpricing increases with a larger ? and $\beta$ as well as with a smaller a and $d$. That is, the larger the degree of uncertainty with respect to project quality, measured by ?, and the less pressing the liquidity constraint of the VC (the larger $ß$ ), the more willing the young $\mathrm{VC}$ is to invest in reputation via underpricing. Thus, albeit via a very different line of arguments we arrive at the same conclusion as other papers on underpricing (see, e.g., Beatty and Ritter, 1986; Grinblatt and Hwang, 1989). Furthermore, just as our paper does, Welch (1989) hypothesizes that underpricing is negatively correlated with volatility in the secondary market. As underpricing in our model is part of a fully revealing signaling equilibrium, there is no need for further price adjustments and secondary market volatility will be low.

In addition, our model claims that a young VC with a smaller expected proportion of high-quality projects is forced to offer a higher degree of underpricing, since the po-

\footnotetext{
14 A further extension of the basic argument is to allow the difference between the experienced and the inexperienced VCs to persist for more than one period. Analyzing this possibility strengthens our argument, at the cost of a significant extension of the calculations: we find for a larger parameter range that a reputational equilibrium with underpricing exists.
} 
tential cost of cheating is less pronounced in this case, thus necessitating a high level of underpricing.

The (young) VCs' incentive to underprice may have obvious repercussions on the investment process of this particular class of VCs. Good-type firms could anticipate the incentive of the $\mathrm{VC}$ and hence would require compensation for this, since underpricing reduces its expected revenue from the IPO. This would, given that potential portfolio firms anticipate this correctly and can observe the characteristics of VCs, impose an additional cost on (young) VCs without affecting, however, our line of argument.

\section{Concluding remarks}

The purpose of the present analysis was to investigate the disinvestment decision of venture capital firms in the course of an initial public offering. Due to informational asymmetries product quality is only revealed after the IPO period. Using a repeated game framework we asked whether (and if so, how) expected sanctions in future periods can force VCs who might otherwise falsely report the quality of their venture to report them correctly and allow for disinvestment in the IPO period at the true project values. This avoids the welfare costs associated with disinvestment decisions in the course of an IPO.

In addition, we investigated under which circumstances VCs may have an incentive to engage themselves in their ventures even after the IPO period. We went on to provide a previously unexplored reason for underpricing in the course of a venture capital-backed IPO. In our setting, underpricing serves as a device for young VCs to credibly invest in the building up of reputation, which especially for first time funds is so often urgently needed. 
Our analysis provides a number of explanations for stylized facts and hypotheses which can be drectly tested by using available data for venture and non-venture backed IPOs.

First, we provide an explanation for a number of characteristics associated with a "hot-issue" market. With a "hot-issue" market (i.e., with a low ß) what emerges is a pooling equilibrium with early disinvestments associated with a high degree of price uncertainty. This is reminiscent of the grandstanding hypothesis for early disinvestments put forward by Gompers (1996). But in contrast to him we do not focus on the timing of the IPO, but rather on the disinvestment decision of the VC. In addition, and in contrast to his argument, with us early selling does not have any informational content (i.e. does not send a signal to potential investors) but rather results from a high degree of uncertainty.

Second, we find that a high market share on the part of an individual VC (i.e., a high d) facilitates the building up of reputation, together with a high degree of credibility and low price uncertainty. We should therefore expect that experienced VCs with a high market share build up reputation, disinvest early, and are able to sell even their high-quality ventures at close to their true value. This is in line with Lin and Smith (1998), who find with US data that only VCs that sell during the IPO have wellestablished reputations. It can also be interpreted as explaining the empirical observation that markets react favorably to the presence of (seasoned) venture capital financing at the time of an IPO (see Barry et al. 1990; Megginson and Weiss, 1991).

Third, we show that a careful selection of ventures on the one hand, and late-stage investment in the value of the portfolio firms via intense management support on the other hand, constitute clear substitutes. In our model, VCs with an expected 
preponderance of high-quality firms (i.e., a high a) have little incentive to undertake investments in the improvement of firm value via intense management support in late stages. This suggests the formation of clientele groups. Typical venture capitalists who are highly specialized in active investment (i.e., providing intense management support) will disinvest late and provide very little price uncertainty. They will sell "mature" firms. More conventional financiers, who have little competitive edge in the area of "active" investment, will disinvest early and provide for a higher degree of price uncertainty.

Fourth, VCs engaged in high-risk ventures (i.e., with a high ?) have a higher incentive to establish a reputation for selling high-quality ventures at their true value and not reporting falsely on the quality of their ventures. Hence, for them the credible building up of reputation should be facilitated, leading to early disinvestments and little price uncertainty. A final hypothesis emerging from our analysis is that especially unseasoned VCs have an incentive to engage in underpricing, whereas seasoned VCs do not need to underprice. This hypothesis is in line with empirical findings on the US market (see Muscarella and Vetsuypens, 1989; Gompers, 1996 for VCs; Johnson and Miller, 1988, Carter and Manaster, 1990 for investment bankers in general). 


\section{Appendix: An Alternative to the Basic Model}

In the main part of the paper we assume that in the class of ventures sold via an IPO there are only two different types, the value of which amounts to either 1 or $(1+?)$. The VCs have the choice between selling the complete venture at the time of the IPO $(t=1)$ or a later period $(t=2)$, when the true value of the venture has become common knowledge. With alternative modeling there is an infinite number of types to be sold, which are continuously distributed over the interval $[1 ;(1+?)]$. In this case, the VC may signal the true quality of the venture by their choice of the part ?, which is sold to the public at time $t=1$. This kind of signaling may succeed, because waiting is generally costly $(ß<1)$. Furthermore, better types have to bear lower costs of waiting because at time $t=2$ the (in their case relatively high) true value is revealed for sure. This avoids a pooling with the less good types. Therefore, the analytical prerequisites for a signaling equilibrium are fulfilled.

In what follows, we assume that the investors estimate the value of the venture by means of looking at the part ?: $\mathrm{V}(?)=\mathrm{f}(?)$. Presumably (and still to be proven), the proportion sold at time $\mathrm{t}=1$ is negatively correlated with the value of the venture.

Given this setting, the wealth $\mathrm{W}$ of a VC with a venture of a true value V, selling a share ? of the venture at the price of $f(?)$ immediately and the remaining part (1-?) in $\mathrm{t}=2$ at the true value $\mathrm{V}$, which has become common knowledge by that time, amounts to

$$
\mathrm{W}(\mathrm{V}, ?)=? \cdot \mathrm{f}(?)+\mathrm{B} \cdot(1-?) \cdot \mathrm{V}
$$

The following conditions are necessary for a signaling equilibrium: First, the investors have to build rational expectations: 


$$
f(?)=V \text {. }
$$

Second, the VC has to maximize their wealth by choosing the correct signal (incentive compatibility):

$$
\begin{aligned}
& \frac{\partial \mathrm{W}(\mathrm{V}, ?)}{\partial ?}=? \cdot \mathrm{f}^{\prime}(?)+\mathrm{f}(?)-\beta \cdot \mathrm{V}=0 \\
& \frac{\partial^{2} \mathrm{~W}(\mathrm{~V}, ?)}{\partial ?}=2 \cdot \mathrm{f}^{\prime}(?)+? \cdot \mathrm{f}^{\prime \prime}(?)<0 .
\end{aligned}
$$

Inserting eq. (A1) into eq. (A2) and solving the resulting differential equation leads to

$$
f(?)=C \cdot ?^{-(1-\beta)},
$$

where the integration constant $\mathrm{C}$ still has to be evaluated. As conjectured, $\mathrm{f}(\cdot)$ is indeed a decreasing function because of $\beta<1$. It can easily been shown that the solution (A4) meets condition (A3), as well.

By determining the integration constant, the signaling equilibrium becomes unambiguous. A useful criterion is to minimize total signaling costs. This is achieved by imposing no costs on the lowest type $(\mathrm{V}=1)$. I.e., the lowest type immediately sells off the complete venture $\left[?^{*}(\mathrm{~V}=1)=1\right]$. Therefore,

$$
\mathrm{f}(1)=\mathrm{C} \cdot ?^{-(1-\beta)}=1
$$

has to hold, which implies

$$
f(?)=?^{-(1-\beta)},
$$

and allows the following conclusions:

1) Only the lowest type, $\quad V=1$, sells off the complete venture immediately. This follows directly from eq. (A5). 
2) The better the venture, the lower is the proportion sold at time $t=1$. This follows from inverting (A6) to

$$
?^{*}=\mathrm{V}^{-\frac{1}{1-\beta}}
$$

with ?* being a decreasing function of $\mathrm{V}$ because of $\beta<1$.

3) The lowest share sold, ? $\min$, corresponds to the highest possible value of the venture, $(1+?) . \quad$ min is strictly bounded away from zero, because

$$
0<?_{\min }=(1+?)^{-\frac{1}{1-\beta}}<1
$$

As a result, there will not be any $\mathrm{VC}$ choosing not to divest at all at time $\mathrm{t}=1$.

As is well known, self-selection models with competition on the uninformed side may have the unfortunate property of "lower end unraveling". I.e., investors may offer alternative IPO contracts which lead to a partial pooling at the lower end and imply a positive profit for the investors. As a result, from the bottom to the top the signaling argument unravels.

With respect to this problem, Riley (1985) has shown that there are two conditions each of which is sufficient for a stable signaling equilibrium.

First, the lowest type has no incentive to enter the market anyway. In the IPO model of Leland and Pyle (1977), e.g., this requirement is met. The revenues of the IPO are used to finance an additional project. Therefore, firms with negative NPV projects choose not to enter the market in a fully revealing signaling equilibrium. In our model, the initial outlay for the venture is sunk. Therefore, the VC sells the venture at the highest possible price. As a result, there does not exist a lower bound for the quality of a venture to be sold via an IPO in our model. But the Leland and Pyle property may be in- 
troduced into our model by the additional assumptions, that VCs suffer additional costs if very low valued ventures are sold via an IPO (instead via a trade-sale or a buy-back) or that VC with very high valued venture reap some additional profits doing an IPO. While these assumptions are ad hoc, technically, they are well in line with the grandstanding hypothesis of Gompers (1996).

Second, the marginal net profit of signaling has to be sharply increasing at the lower end of quality. In our model this means, the discount factor $\beta$ has to be sufficiently high. For the example of a uniform distribution of types it is quite easy to check, that $\beta$ has to be virtually one for very small values of ?, where for higher values of ? the critical discount factor allows for a reasonable range of parameters supporting an signaling equilibrium.

But even if a signaling equilibrium of the Nash-type fails to exist, there might be a less demanding, "reactive" equilibrium (Riley 1985). In this kind of equilibrium, investors examining the possibility of alternative contracts will anticipate that other investors will react to profit generating alternative offers. If the alternative offers do not earn any profit in case of a reaction by the other investors, the initial equilibrium will prevail.

Overall, the existence of a signaling equilibrium which supports the above cited conclusions 1) to 3) seems well justified. 


\section{References}

Allen, F., AND G. R. FAUlhaber (1989). Signaling by underpricing in the IPO market, Journal of Financial Economics 23, 303-323.

AMIT, R., J. BRANDER AND C. ZOTT (1998). Why do venture capital firms exist? Theory and Canadian evidence, Journal of Business Venturing 13, 441-446.

BARON, D. P. (1982). A model of the demand for investment banking advising and distribution services for new issues, Journal of Finance 37, 955-976.

Barry, C., C. Muscarella, J. W. Peavy III, And M. Vetsuypens (1990). The role of venture capital in the creation of public companies: Evidence from the going public process, Journal of Financial Economic*s 27, 447-471.

BEAtTy, R. P., AND J. P. RTTTER (1986). Investment banking, reputation, and the underpricing of initial public offerings, Journal of Financial Economics 15, 213-232.

BLACK, B., AND R. GLSON (1998). Venture capital and the structure of capital markets: Bank versus stock markets, Journal of Financial Economics 47, 243-277.

Booth, J. R., AND R. L. SMITH (1986). Capital raising, underwriting and the certification hypothesis, Journal of Financial Economics 15, 261-281.

CARTER, R. B., AND S. MANASTER (1990). Initial public offerings and underwriter reputation, Journal of Finance 45, 1045-1067.

FRIEDMAN, J. (1971). A non-cooperative equilibrium for supergames, Review of Economic Studies 38, 1-12.

GOMPERS, P. A. (1996). Grandstanding in the venture capital industry, Journal of Financial Economics 43, 133-156. 
GOMPERS, P. A., AND J. LERNER (1998). Venture capital distributions: short-run and long-run reactions, Journal of Finance 53, 2161-2183.

Gompers, P. A., AND J. LeRnER (2000). The Venture Capital Cycle, MIT Press, Cambridge (Mass.)

Grinblatt, S. I., AND C. Y. HwANG (1989). Signalling and the pricing of new issues, Journal of Finance 44, 393-420.

HELlmANN, T. (1998). The allocation of control rights in venture capital contracts, Rand Journal of Economics 29, 57-76.

JOHNSON, J. M., AND R. E. MiLLER (1988). Investment banker prestige and the underpricing of initial public offerings, Financial Management 17, No. 2, 19-29.

KLEIN, B., AND K. B. LEFFLER (1981). The role of market forces in assuring contractual performance, Journal of Political Economy 89, 615-641.

KREPS, D. M., AND R. WILSON (1982). Reputation and imperfect information, Journal of Economic Theory 27, 253-279.

LELAND, H. E., AND D. H. PYLE (1977). Informational asymmetries, financial structure, and financial intermediation, Journal of Finance 32, 371-387.

LIN, T., AND R. SMITH (1998). Insider reputation and selling decisions: the unwinding of venture capital investments during equity IPOs, Journal of Corporate Finance 4, 241263.

MEGGINSON, W. L. AND K. A. WEISS (1991). Venture capital certification in initial public offerings, Journal of Finance 46, 879-903.

MILGROM, P., AND J. ROBERTS (1982). Predation, reputation and entry deterrence, Journal of Economic Theory 27, 280-312. 
MusCARELla, C., AND M. VeTSUYPENS (1989). Initial public offerings and information asymmetry, Unpublished working paper, Pennsylvania State University and Southern Methodist University.

RILEY, J. G. (1985). Competition with hidden knowledge, Journal of Political Economy 93, 958-976.

RocK, K. (1986). Why new issues are underpriced, Journal of Financial Economics 15, $187-212$.

SAHLMAN, W. (1990). The structure and governance of venture capital organizations, Journal of Financial Economics 27, 473-521.

SHAPIRO, C. (1983). Premiums for high quality products as returns to reputation, Quarterly Journal of Economics 97, 659-679.

STOCKEN, P. C. (2000). Credibility of voluntary disclosure, Rand Journal of Economics $31,359-374$.

WELCH, I. (1989). Seasoned offerings, imitation costs, and the underpricing of initial public offerings, Journal of Finance 44, 421-449. 


\section{Tables and figures}

\begin{tabular}{|c|ccc|cc|}
\hline & \multicolumn{3}{|c|}{ Parameters } & \multicolumn{2}{c|}{ Critical values } \\
& $\alpha$ & $\delta$ & $\Delta$ & $\beta_{\min }=\beta_{P}$ & $\beta_{\max }=\beta_{R}$ \\
\hline Example 1 & 0.2 & 0.9 & 0.1 & 0.9273 & 0.9495 \\
Example 2 & 0.5 & 0.9 & 0.1 & 0.9545 & 0.9798 \\
Example 3 & 0.8 & 0.9 & 0.5 & 0.9333 & 0.9537 \\
Example 4 & 0.5 & 0.9 & 0.2 & 0.9167 & 0.9630 \\
Example 5 & 0.9 & 0.95 & 0.2 & 0.9833 & 0.9903 \\
\hline
\end{tabular}

Table I: Examples of reputational equilibria.

\begin{tabular}{|c|c|c|c|c|c|c|c|}
\hline & \multicolumn{5}{|c|}{ Parameters } & \multicolumn{2}{|c|}{ Critical values } \\
\hline & $a_{1}$ & $\mathrm{a}$ & $\mathrm{d}_{1}$ & $\mathrm{~d}_{2}$ & $?$ & $\beta_{\min }=\max \left\{\beta_{\mathrm{P}} ; \beta_{\mathrm{R}}^{\mathrm{Y}}\right\}$ & $\beta_{\max }=\min \left\{\beta_{\mathrm{R}}^{\mathrm{E}} ; \beta_{\mathrm{R}}^{\text {underpr }}\right\}$ \\
\hline Case 1 & - & 0.5 & 0.7 & 0.85 & 0.5 & 0.8571 & 0.8824 \\
\hline Case 2 & - & 0.5 & 0.75 & 0.85 & 0.5 & 0.8667 & 0.8824 \\
\hline Case 3 & - & 0.5 & 0.75 & 0.85 & 0.25 & 0.9200 & 0.9294 \\
\hline Case 4 & - & 0.5 & 0.6 & 0.75 & 0.5 & 0.8333 & 0.7778 \\
\hline Case 5 & - & 0.2 & 0.7 & 0.85 & 0.5 & 0.7333 & 0.7059 \\
\hline Case 6 & 0.4 & 0.7 & 0.85 & 0.85 & 0.5 & 0.9000 & 0.9160 \\
\hline Case 7 & 0.4 & 0.7 & 0.9 & 0.9 & 0.5 & 0.9000 & 0.9471 \\
\hline
\end{tabular}

Table II: Examples for the existence and non-existence of a reputational equilibrium with underpricing. 


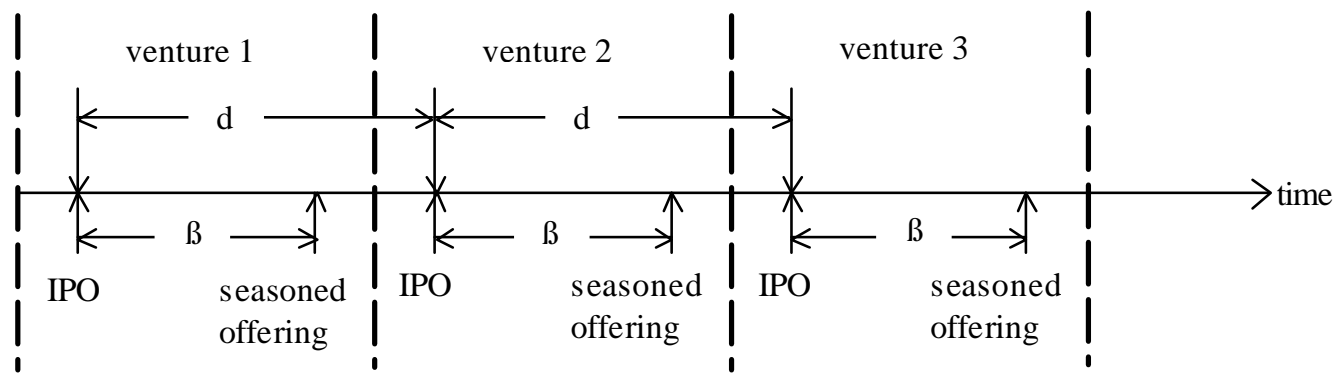

Figure 1: The distinction between $\beta$ and $d$. 


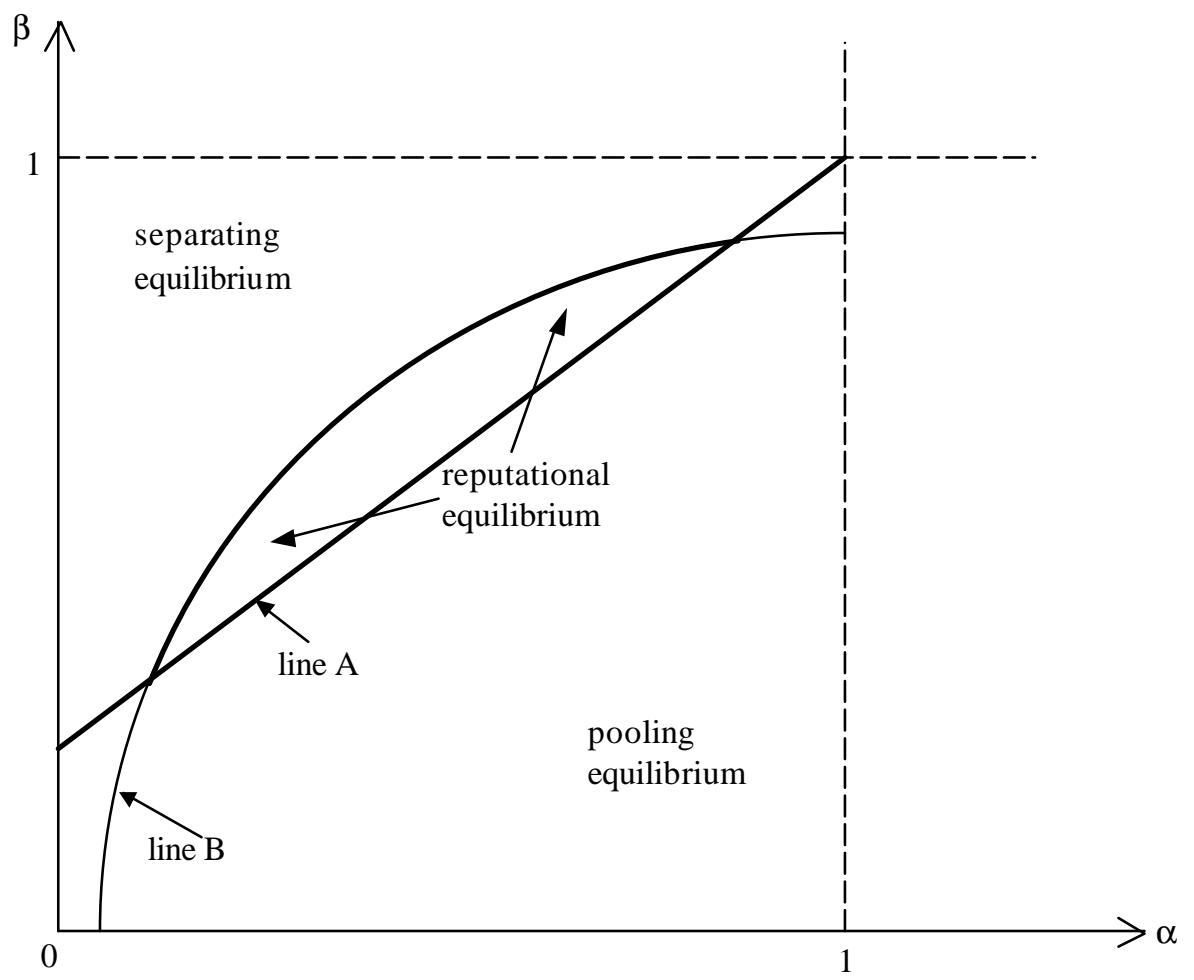

Figure 2: The reputational equilibrium. 


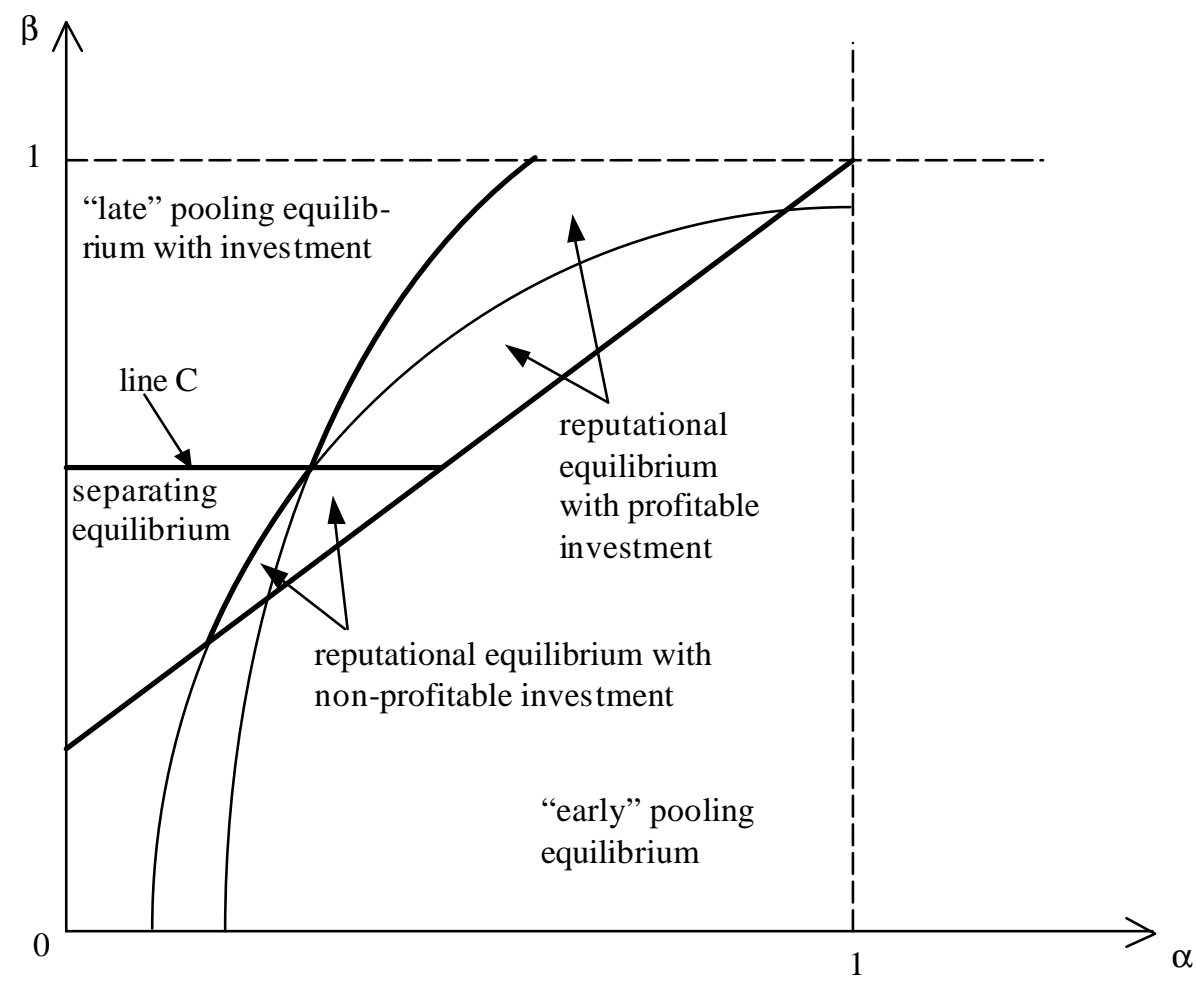

Figure 3: Equilibria with value-enhancing investment. 


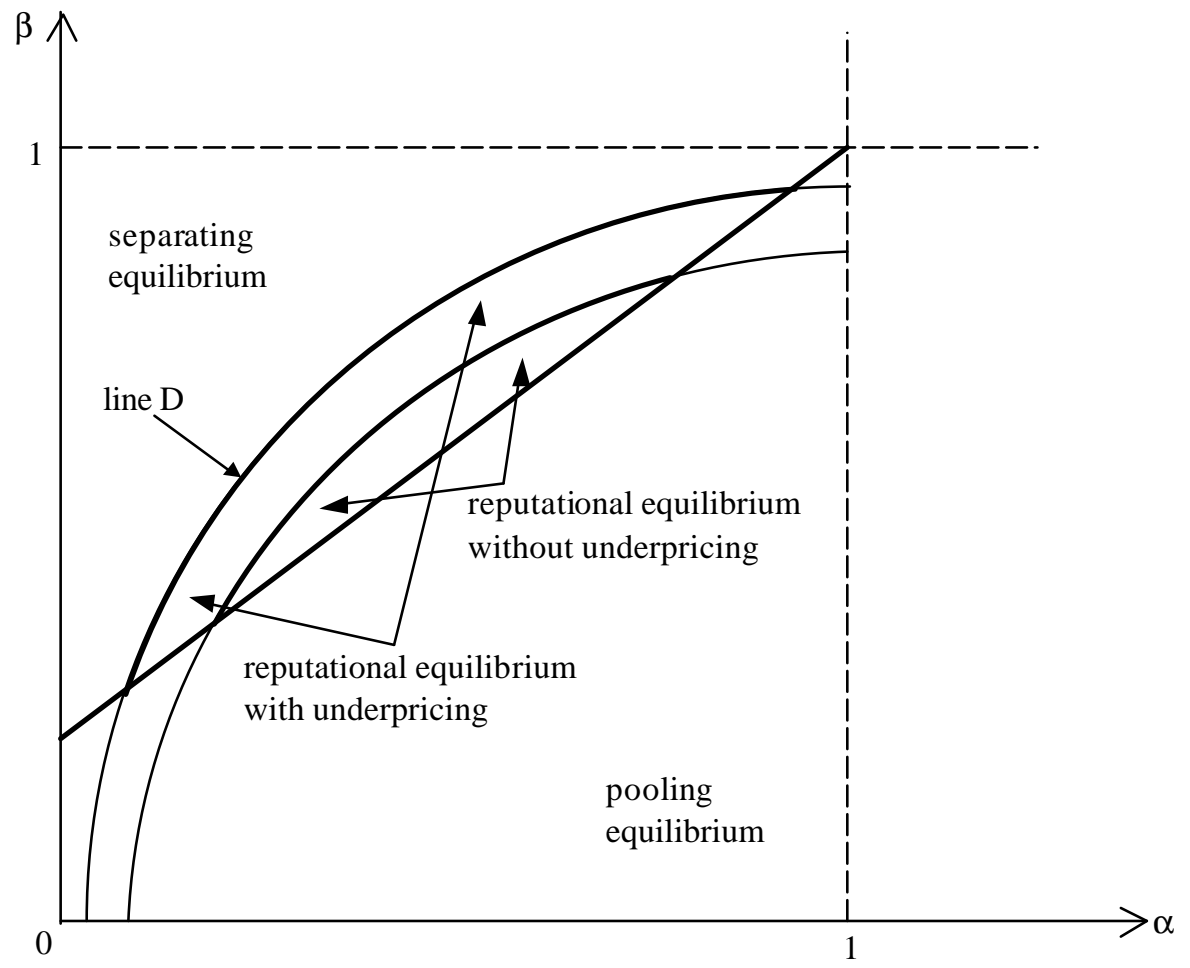

Figure 4: Reputational equilibria with and without underpricing. 


\section{CFS Working Paper Series:}

\begin{tabular}{ll} 
No. & Author(s) \\
\hline $2001 / 10$ & $\begin{array}{l}\text { Olaf Ehrhardt } \\
\text { Eric Nowak }\end{array}$ \\
$2001 / 11$ & Daniel Gross \\
$2001 / 12$ & Daniel Gross \\
& \\
$2002 / 01$ & $\begin{array}{l}\text { Stefan Feinendegen } \\
\text { Daniel Schmidt } \\
\text { Mark Wahrenburg }\end{array}$ \\
\hline
\end{tabular}

2002/02 Issam Hallak

2002/03 Raimond Maurer Christian Schlag

2002/04 Holger Claessen
Stefan Mittnik

2002/05 Bernd Kaltenhäuser

2002/06 Erik Theissen

2002/07 Werner Neus Uwe Walz
Title

Private Benefits and Minority Shareholder

Expropriation - Empirical Evidence from IPOs of German Family-Owned Firms

Country-Specific and Global Shocks

in the Business Cycle

Trade Flows and the International Business Cycle

Die Vertragsbeziehung zwischen Investoren und Venture Capital-Fonds: Eine empirische Untersuchung des europäischen Venture Capital-Marktes

Price Discrimination on Syndicated Loans and the Number of Lenders: Empirical Evidence from the Sovereign Debt Syndication

Money-Back Guarantees in Individual Pension

Accounts: Evidence from the German Pension Reform

Forecasting Stock Market Volatility and the Informational Efficiency of the DAX-index Options Market

Return and Volatility Spillovers to Industry Returns: Does EMU Play a Role?

Internalisierung und Marktqualität: Was bringt Xetra Best?

Exit Timing of Venture Capitalists in the Course of an Initial Public Offering

Copies of working papers are available at the Center for Financial Studies or can be downloaded (http://www.ifk-cfs.de). 